\title{
Commentary KL-6 in acute lung injury: will it leave its mark? Murali Shyamsundar ${ }^{1}$ and Danny F McAuley²
}

\author{
Research fellow, Royal Victoria hospital/Queen's University of Belfast, Respiratory Research Group, Microbiology Building, Grosvenor Road, Belfast, \\ BT12 6BA \\ Senior lecturer/Consultant intensive care physician, Royal Victoria hospital/Queen's University of Belfast, Respiratory Research Group, Microbiology \\ Building, Grosvenor Road, Belfast, BT12 6BA
}

Corresponding author: Danny McAuley, d.f.mcauley@qub.ac.uk

Published: 31 March 2008

This article is online at http://ccforum.com/content/12/2/121

(c) 2008 BioMed Central Ltd

Critical Care 2008, 12:121 (doi:10.1186/cc6827)

See related research by Nathani et al., http://ccforum.com/content/12/1/R12

\begin{abstract}
Studies have indicated that measuring biochemical measures of epithelial injury in plasma and alveolar fluid may be useful in predicting outcome in acute lung injury. The present commentary briefly reviews the evidence supporting the use of these biochemical biomarkers of epithelial injury in acute lung injury, and in particular KL-6, as well as their limitations. The article additionally proposes the need for physiological markers of epithelial function to complement current biochemical biomarkers.
\end{abstract}

In the previous issue of Critical Care Nathani and colleagues have assessed KL-6, a specific marker of type 2 alveolar epithelial cell injury, as a biomarker in acute lung injury (ALI) [1]. Biomarkers allow identification of patients at risk of developing disease or can be used as surrogate measures for clinical outcomes. Additionally, measuring biological markers may be a valuable tool in understanding disease pathogenesis. In ALI, the alveolar capillary barrier is disrupted and the alveolar epithelial cell function is critical to the recovery from ALI/acute respiratory distress syndrome (ARDS) [2]. This knowledge provides a rationale for measurement of alveolar epithelial cell injury using surrogate biochemical measures such as KL-6, as a biomarker of ALI.

In the study of Nathani and colleagues, plasma and bronchoalveolar lavage samples were collected following inclusion and on day 4 from 30 ventilated $A L I$ patients, from 12 patients at risk of developing $A L I$ and from 10 nonsmoking volunteers free of respiratory disease The study therefore had the benefit of allowing the investigators to look at KL-6 both in physiological and pathological states. The important findings from the study are that plasma KL- 6 levels are increased in patients with $\mathrm{ALI}$, plasma KL-6 correlates with the severity of lung injury and plasma $K L-6$ is significantly elevated in nonsurvivors compared with survivors. Furthermore bronchoalveolar lavage KL-6 is elevated in patients with $\mathrm{ALI}$ and is higher in nonsurvivors. KL-6 did not identify patients at risk of developing ALI. These findings extend the previous data showing $\mathrm{KL}-6$ is elevated in plasma and epithelial lining fluid in $\mathrm{ALI}[3,4]$.

In relation to $\mathrm{KL}-6$ in $A L I$, questions that still remain to be answered include the specificity of the type 2 epithelial cell as the source of $\mathrm{KL}-6$ [5] as well as a need to confirm whether KL-6 elevation reflects epithelial cell injury, regeneration or secretion in response to inflammatory mediators. In addition, mechanical ventilation is known to cause epithelial injury [6], and an important area in which biomarkers may be valuable is in the assessment of ventilatorassociated lung injury. Increased surfactant protein D is associated with injurious ventilation strategies [7], and it would be interesting to know the effects of mechanical ventilation on $\mathrm{KL}-6$.

Regardless of these outstanding questions, Nathani and colleagues' work - together with other data showing that elevated surfactant protein D, a type 2 epithelial cell product, is associated with a worse clinical outcome in ALI/ARDS [7] and that the Receptor for Advanced Glycation End-products, an alveolar type 1 epithelial cell-associated protein, is increased in patients with ALI [8] - implicates epithelial cell damage as an important determinant of outcome and implies the potential for alveolar epithelial cell biomarkers to predict outcome in ALI. Further, these data support the central role of epithelial injury in the pathogenesis of ALI.

Notable limitations of all these surrogate biomarkers exist; they do not directly measure epithelial function, and they

$\mathrm{ALI}=$ acute lung injury; ARDS $=$ acute respiratory distress syndrome. 
require laboratory analysis and therefore cannot be performed by a clinician at the bedside. Additionally, there is no biomarker of epithelial function that reliably identifies patients at risk of ALI who will develop ALI. There is therefore a need to develop additional functional measures of epithelial activity.

One such functional measure that merits further research is nasal potential difference. The resolution of pulmonary oedema from the alveolar space, which is dependent on alveolar fluid clearance, is critical to the recovery from ALI/ARDS. Alveolar fluid clearance depends on active transport of sodium across a functioning alveolar epithelium. Ion transport across the epithelium generates a transepithelial potential difference [9]. Although this cannot be measured at the alveolus, the potential difference can be measured readily across the nasal epithelium. Measuring nasal potential difference is a simple noninvasive measurement easily undertaken repeatedly at the bedside. In an animal model, measurement of nasal potential difference correlated with alveolar fluid clearance [10]. This observation supports the hypothesis that nasal potential difference measurement may be a surrogate marker for alveolar epithelial function. Furthermore, premature infants with pulmonary oedema [11] and patients susceptible to high-altitude pulmonary oedema [12] have reduced nasal transepithelial sodium resorption, as measured by the baseline nasal potential difference, indicating that nasal potential difference measurement may be able to identify patients at risk of developing ALI.

Although further work validating such functional measures of epithelial activity is required, it is probable that as well as biochemical measures such as KL-6, as demonstrated by Nathani and colleagues, future biomarkers in ALI will combine both biochemical and functional measures.

\section{Competing interests}

The authors declare that they have no competing interests.

\section{References}

1. Nathani N, Perkins GD, Tunnicliffe W, Murphy N, Manji M, Thickett DR: KL- 6 is a marker of alveolar inflammation but not infection in patients with ARDS. Crit Care 2008, 12:R12.

2. Matthay MA, Wiener-Kronish JP: Intact epithelial barrier function is critical for the resolution of alveolar edema in humans. Am Rev Respir Dis 1990, 142:1250-1257.

3. Sato H, Callister MEJ, Mumby S, Quinlan GJ, Welsh KI, duBois RM, Evans TW: KL-6 levels are elevated in plasma from patients with acute respiratory distress syndrome. Eur Respir J 2004, 23:142-145

4. Ishizaka A, Matsuda T, Albertine $\mathrm{KH}$, Koh H, Tasaka S, Hasegawa $\mathrm{N}$, Kohno N, Kotani T, Morisaki H, Takeda J, Nakamura M, Fang X, Martin TR, Matthay MA, Hashimoto S: Elevation of KL-6, a lung epithelial cell marker, in plasma and epithelial lining fluid in acute respiratory distress syndrome. Am J Physiol Lung Cell Mol Physiol 2004, 286:L1088-L1094.

5. Kase S, Nobuyoshi K, Namba K, Miyazaki A, Yoshida K, Ishikura K, Ikeda M, Nakashima T, Ohno S: Elevation of serum Krebs von den Lunge- 6 levels in patients with tubulointerstitial nephritis and uveitis syndrome. Am J Kidney Dis 2006, 48:935-941.

6. Frank JA, Gutierrez JA, Jones KD, Allen L, Dobbs L, Matthay MA: Low tidal volume reduces epithelial and endothelial injury in acid-injured rat lungs. Am J Respir Crit Care Med 2002, 165: 242-249.

7. Eisner MD, Parsons P, Matthay MA, Ware L, Greene K: Plasma surfactant protein levels and clinical outcomes in patients with acute lung injury. Thorax 2003, 58:983-988.

8. Uchida T, Shirasawa M, Ware LB, Kojima K, Hata Y, Makita K Mednick G, Matthay ZA, Matthay MA: Receptor for advanced glycation end-products is a marker of type I cell injury in acute lung injury. Am J Respir Crit Care Med 2006, 173:1008-1015.

9. Knowles M, Gatzy J, Boucher R: Increased bioelectric potential difference across respiratory epithelia in cystic fibrosis. $N$ Engl J Med 1981, 305:1489-1495.

10. Egli M, Duplain H, Lepori M, Cook S, Nicod P, Hummler E, Sartori $\mathrm{C}$, Scherrer U: Defective respiratory amiloride-sensitive sodium transport predisposes to pulmonary oedema and delays its resolution in mice. J Physio/ 2004, 560:857-865.

11. Barker PM, Gowen CW, Lawson EE, Knowles MR: Decreased sodium ion absorption across nasal epithelium of very premature infants with respiratory distress syndrome. $J$ Pediatr 1997, 130:373-377.

12. Sartori C, Allemann Y, Duplain H, Lepori M, Egli M, Lipp E, Hutter D, Turini P, Hugli O, Cook S, Nicod P, Scherrer U: Salmeterol for the prevention of high-altitude pulmonary edema. $N$ Engl J Med 2002, 346:1631-1636. 